\title{
Laterial Performance of Drilled Shaft Considering Nonlinear Soil and Structure Material Behavior
}

Chao-Kuang Hsueh

Ph.D. Candidate, Department of Harbor and River Engineering, National Taiwan Ocean University, Keelung, Taiwan 202.

San-Shyan Lin

Professor, Department of Harbor and River Engineering, National Taiwan Ocean University, Keelung, Taiwan 202., sslin@mail.ntou.edu.tw

Shuh-Gi Chern

Professor, Department of Harbor and River Engineering, National Taiwan Ocean University, Keelung, Taiwan 202.

Follow this and additional works at: https://jmstt.ntou.edu.tw/journal

Part of the Civil and Environmental Engineering Commons

\section{Recommended Citation}

Hsueh, Chao-Kuang; Lin, San-Shyan; and Chern, Shuh-Gi (2004) "Laterial Performance of Drilled Shaft Considering Nonlinear Soil and Structure Material Behavior," Journal of Marine Science and Technology. Vol. 12: Iss. 1, Article 8. DOI: 10.51400/2709-6998.2221

Available at: https://jmstt.ntou.edu.tw/journal/vol12/iss1/8

This Research Article is brought to you for free and open access by Journal of Marine Science and Technology. It has been accepted for inclusion in Journal of Marine Science and Technology by an authorized editor of Journal of Marine Science and Technology. 


\section{Laterial Performance of Drilled Shaft Considering Nonlinear Soil and Structure Material Behavior}

\section{Acknowledgements}

The authors would like to thank the tested data provided from the Bureau of Taiwan High Speed Rail and the supports of the National Center for High-performance Computing (NCHC) for their computing programs and servers that are used in this study. 


\title{
LATERAL PERFORMANCE OF DRILLED SHAFT CONSIDERING NONLINEAR SOIL AND STRUCTURE MATERIAL BEHAVIOR
}

\author{
Chao-Kuang Hsueh*, San-Shyan Lin**, and Shuh-Gi Chern**
}

Key words: drilled shaft, pile, nonlinear material, structure, lateral load, finite element.

\section{ABSTRACT}

In addition to nonlinear soil behavior has been assumed in conventional analytical method, performance of the laterally loaded drilled-shaft is also strongly influenced by possible concrete cracking, steel yielding, and shaft/soil separation and interaction. However, these factors are often neglected in the most of available methods and studied results. The main purpose of this paper is to investigate the importance of the above-mentioned effects on lateral performance of drilled reinforced-concrete shaft. The finite element code, ABAQUS, which is available in the three-dimensional analysis is adopted for taking into account the nonlinearity in shaft and soil materials, pilesoil interaction and nonlinear geometric properties of the shaft/soil system in the analysis. Also, infinite elements are used to simulate unbounded boundary condition. One of the lateral pile load tests results of high-speed railway system in Taiwan is used to simulate the real behavior of drilled shaft subjected to lateral load. The numerical results show that the nonlinearity of material and geometry strongly affects the shaft deflection, steel stress distribution, concrete cracking state, soil uplift in front of the shaft, and separation between shaft/soil interfaces that is behind the shaft and along its depth.

\section{INTRODUCTION}

Two main approaches, the sub-grade reaction method and the elastic solution, are often used for analyses of piles subjected to lateral loads. Both linear and nonlinear springs for soil properties can be utilized with the sub-grade reaction approach but pile shaft is often treated as a linear material. Although few researches are available to take into account nonlinear pile behavior in their studies, such as Reese and Wang [12], Lin [7], Lin [8], Chiou [4], and Ng et al. [11], and simplified p-y type soil resistance assumption is used. The elastic approach considers the soil that is a continu-

Paper Submitted 11/03/03, Accepted 11/25/03. Author for Correspondence: San-Shyan Lin.E-mail: sslin@mail.ntou.edu.tw.

*Ph.D. Candidate, Department of Harbor and River Engineering, National Taiwan Ocean University, Keelung, Taiwan 202.

**Professor, Department of Harbor and River Engineering, National Taiwan Ocean University, Keelung, Taiwan 202. ous medium rather than unconnected springs as in the sub-grade reaction method. The input variables can be directly related to measured soil properties, such as its stiffness and its strength in the elastic continuum model. The shortcoming of elastic analyses is that they are rarely realistic because the laterally loaded drilledshafts behave in a nonlinear manner, especially for such reinforced concrete piles. In addition, perfect bonding between pile shaft and soil is usually assumed to simplify analyzed procedure.

In reality, the behavior of drilled shaft subjected to laterally loading is three dimensional in nature. In addition to nonlinear soil and shaft material properties effects, soil-pile interaction and geometric nonlinear effects such as possible separation between shaft and soil due to lateral loading also influence the performance of laterally loaded drilled-shaft. In order to have a better understanding of laterally loaded response of drilled shaft, taking into account possible nonlinear material and geometry effects, the three-dimensional (3-D) finite element method that is available in the famous computer code, ABAQUS [6], is used in this research to investigate the drilled shaft, which is composed of steel reinforcement and concrete, embedded in layered soil conditions. Pre- and post-processings of the finite element meshes are processed via another computer code PATRAN [10]. Nonlinear material properties for concrete cracking, steel yielding and plasticity of soil in the shaft/soil system are considered by using appropriate constitutive models. Possible separation and relative movement between shaft and soil due to lateral loading is also treated in the analysis by using contact command "CONTACT PAIR" available in the software ABAQUS [6].

\section{MATERIAL MODELING}

\section{Concrete model}

In general, concrete tends to have linear and nonlinear behavior within and beyond $30 \%$ of the maximum compressive strength, respectively. After the maxi- 
mum compressive strength is reached, concrete turns to behave softening and begins to crush. Furthermore, concrete tends to crack when the subjected tensile stress is larger than its tensile strength. Material properties used in the nonlinear analysis are given in the following:

Based on the ACI code [1], elastic modulus of the concrete is given as

$$
\begin{aligned}
E_{c} & =57000 \sqrt{f_{c}^{\prime}}(\mathrm{psi}) \approx 4730 \sqrt{f_{c}^{\prime}}(\mathrm{MPa}) \\
& \approx 15000 \sqrt{f_{c}^{\prime}}\left(\mathrm{kg} / \mathrm{cm}^{2}\right)
\end{aligned}
$$

where $f_{c}^{\prime}$ is the peak strength of concrete.

In addition, based on the study by MacGregor [9], the respective strain relevant to the maximum strength is

$$
\varepsilon_{c}=1.81 f_{c}^{\prime} / E_{c}
$$

The ultimate tensile strength or the cracking failure stress of concrete is also adopted from the ACI code [1] and is given as

$$
f_{r}=7.5 \sqrt{f_{c}^{\prime}}(\mathrm{psi}) \approx 2.0 \sqrt{f_{c}^{\prime}}\left(\mathrm{kg} / \mathrm{cm}^{2}\right)
$$

With regard to the yield criterion of the concrete, assuming the material follows the associated flow rule, we have [7]

$$
f_{c}=q-\sqrt{3} a_{0} p-\sqrt{3} \tau_{c}=0
$$

where $a_{0}$ is a constant which is chosen from the ratio of the ultimate stress reached in biaxial compression to the ultimate stress reached in uniaxial compression, $\tau_{c}$ is the yield stress in a state of pure shear stress, and $p$ is the effective stress and can be expressed as:

$$
p=-\frac{1}{3} \operatorname{trace}(\sigma)=-\frac{1}{3} \sigma: \mathrm{I}=-\frac{1}{3}\left(\sigma_{x}+\sigma_{y}+\sigma_{z}\right)=-\frac{I_{1}}{3}
$$

in which $\sigma$ is the stress tensor, $\mathrm{I}$ is the unit matrix, $I_{1}$ is the first invariant of the stress tensor, and following the definition of the Mises equivalent deviatoric stress, $q$ is defined as:

$$
q=\sqrt{\frac{3}{2} S: S}=\sqrt{\frac{3}{2} S_{i j} S_{j i}}=\sqrt{3 J_{2}}
$$

where $S=\sigma+p$ I are the deviatoric stress tensor components, and $J_{2}$ is the second invariant of the deviatoric stress tensor.

Once concrete crack occurs, the material stiffness needs to be adjusted to take into account the cracking effect. Whether concrete is cracked or not is evaluated at integration points of each element, based on the Coulomb line defined as

$$
f_{t}=\hat{q}-\left(3-b_{0} \frac{\sigma_{t}}{\sigma_{t}^{u}}\right) \hat{p}-\left(2-\frac{b_{0}}{3} \frac{\sigma_{t}}{\sigma_{t}^{u}}\right) \sigma_{t}=0
$$

where $\sigma_{t}$ is the equivalent uniaxial tensile stress, $\sigma_{t}^{u}$ is the failure stress in uniaxial tension, $b_{0}$ is a constant which is obtained from the value of the tensile failure stress in a state of biaxial stress when the other nonzero principal stress is at the uniaxial compression ultimate stress value, and $\hat{p}$ and $\hat{q}$ are defined in the same way as $p$ and $q$ in Equations 5 and 6, respectively, except that all stress components associated with open cracks (concrete cracking has occurred) are not included [6].

Fig. 1a is the uniaxial behavior of plain concrete material, which is adopted in the nonlinear numerical analysis.

\section{Steel model}

Steel reinforcing bars are assumed to be elasticplastic axially loaded elements. Discrete reinforcing bars are embedded within the solid element. The elastic-plastic model of steel material used in the nonlinear numerical analysis is shown in Fig. 1b, and the elastic modulus of steel rebar from the ACI code [1] is given as

$$
\begin{aligned}
E_{s} & =29 \times 10^{6}(\text { psi })=2.04 \times 10^{6}\left(\mathrm{~kg} / \mathrm{cm}^{2}\right) \\
& =200,124(\mathrm{MPa})
\end{aligned}
$$

\section{Soil model}

The conventional Mohr-Coulomb materials are used in this paper for soil modeling. Brief review of the model is given in the following:

The failure envelope, familiarized by most of the geotechnical engineers, is expressed as

$$
\tau=c+\sigma \tan \phi
$$

where $\tau$ is the shear stress, $\sigma$ is the normal stress, and $\phi$ is the angle of internal friction.

Based on the Mohr circle, we can obtain

$$
\tau=\frac{\left(\sigma_{1}-\sigma_{3}\right)}{2} \cos \phi
$$

and

$$
\sigma=\frac{\left(\sigma_{1}+\sigma_{3}\right)}{2}-\frac{\left(\sigma_{1}-\sigma_{3}\right)}{2} \sin \phi
$$

where $\sigma_{1}$ is the maximum principal stress, and $\sigma_{3}$ is the minor principal stress. 
Substituting $\tau$ and $\sigma$ into Equation 9, we have

$$
\frac{\left(\sigma_{1}-\sigma_{3}\right)}{2}-c \cos \phi-\frac{\left(\sigma_{1}+\sigma_{3}\right)}{2} \sin \phi=0
$$

\section{FINITE ELEMENT MODELING DESCRIPTION}

For the purpose of this study, how finite element meshes are generated via the software ABAQUS [6] is briefly described. Detailed description regarding how to use ABAQUS is beyond the scope of this paper and can be referred elsewhere. The shaft/soil system is represented by using the 8-node isoparametric solid elements. Similar to the study by Chen and Poulos [3], the infinite field of the soil layers is divided into near field and far field domains. Figs. 2 and 3 give the three-

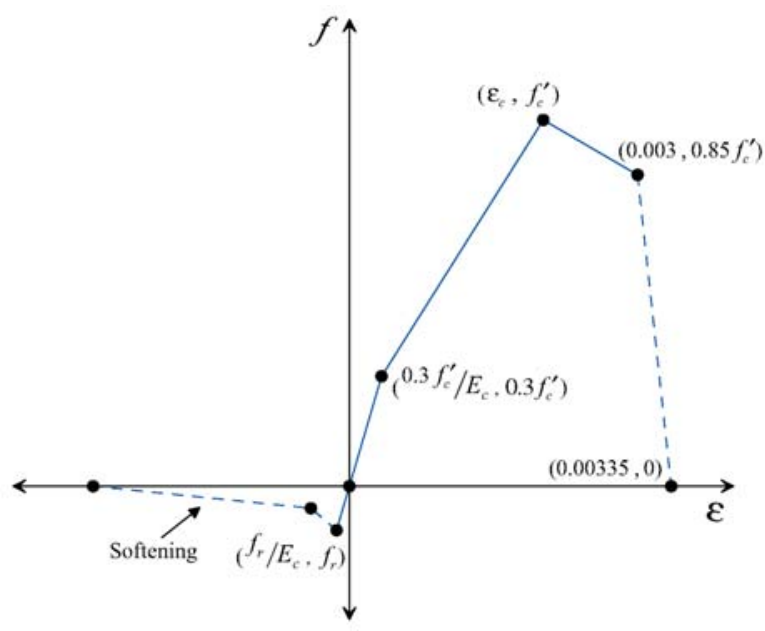

(a)

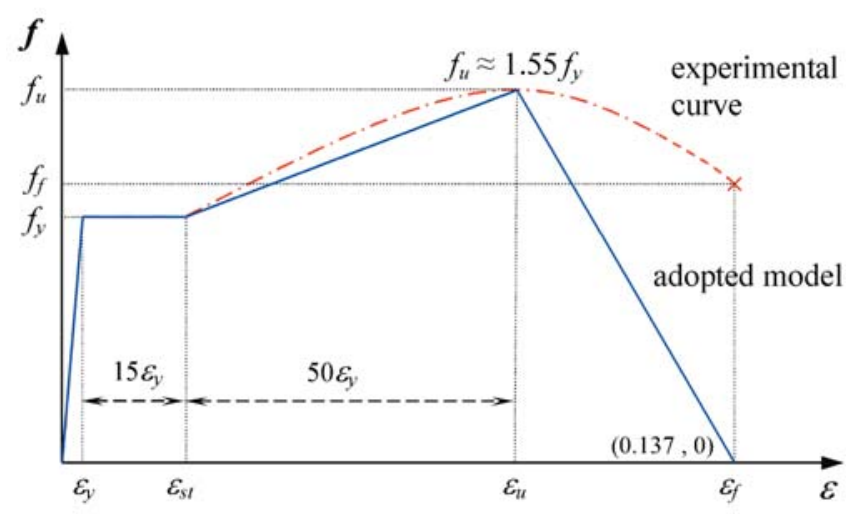

(b)

Fig. 1. The models of concrete and steel materials. dimension and top view of the finite element meshes considered in the numerical simulation and analysis discussed below, including 16,585 elements and 19,445 nodes. The bold-face solid lines that appear in Fig. 3 represent the contact interfaces between the pile shaft and soil, in which possible separation or relative movement between soil and structure can be taken into account in the analyses. The bold-face dash lines indicate the boundary between the near and far field. Infinite elements are used for the soil domain beyond the boundary. Consequently, the elements within the solid lines are pile shaft elements while the elements outside the solid line represent modeling for soil. In addition, initial soil in-situ stress is also considered in the analyses.

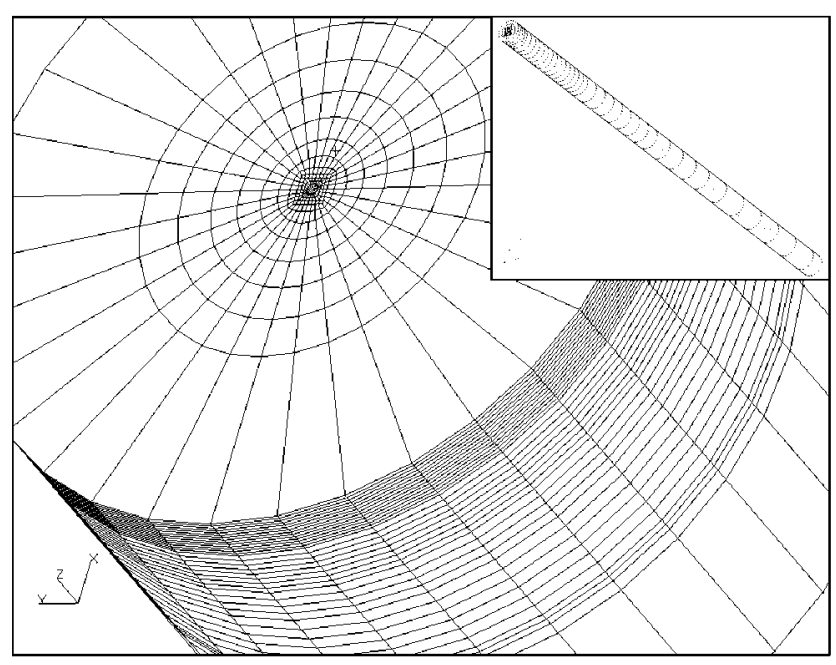

Fig. 2. 3D finite element model.

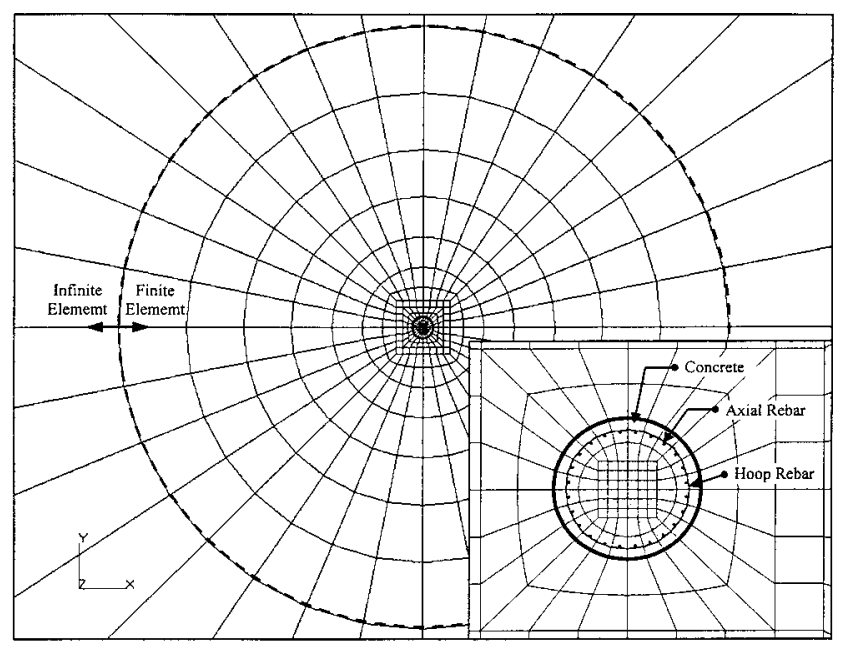

Fig. 3. Top view of finite element meshes. 
Table 1. Simplified soil layers and analyzed parameters on test site

\begin{tabular}{ccccccccc}
\hline $\begin{array}{c}\text { Depth } \\
(\mathrm{m})\end{array}$ & SPT-N & Classification & $\begin{array}{c}\gamma_{t} \\
\left(\mathrm{kN} / \mathrm{m}^{3}\right)\end{array}$ & $\begin{array}{c}E_{s} \\
(\mathrm{kPa})\end{array}$ & $\begin{array}{c}c \\
(\mathrm{kPa})\end{array}$ & $\begin{array}{c}\phi \\
\left({ }^{\circ}\right)\end{array}$ & $v_{s}$ & $K_{o}$ \\
\hline $0-3$ & $1 \sim 5$ & ML/SM & 18.64 & 44584 & 1.0 & 13.5 & 0.4 & 0.63 \\
$3-8$ & $8 \sim 19$ & SM & 18.64 & 49407 & 1.0 & 12 & 0.3 & 0.72 \\
$8-12$ & $4 \sim 12$ & CL & 18.69 & 81935 & 14.81 & 10.8 & 0.45 & 0.78 \\
$12-16$ & $15 \sim 29$ & SM & 18.84 & 96605 & 1.0 & 18.2 & 0.3 & 0.76 \\
$16-22$ & $11 \sim 23$ & CL $\notin$ ASM & 18.84 & 122379 & 1.0 & 16.8 & 0.4 & 0.68 \\
$22-32$ & $9 \sim 27$ & CL & 18.76 & 242855 & 19.6 & 21 & 0.45 & 0.6 \\
$32-40$ & $14 \sim 45$ & SM & 19.07 & 282625 & 1.0 & 25 & 0.3 & 0.55 \\
\hline
\end{tabular}

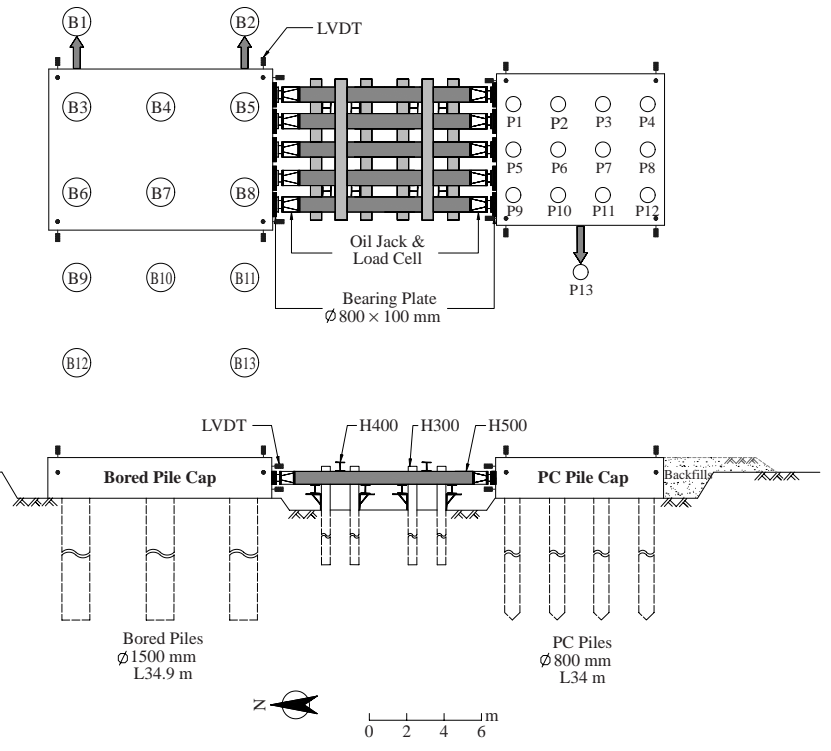

Fig. 4. Layout of laterally loaded piles test [2].

\section{NUMERICAL SIMULATION AND ANALYSIS}

Elevated viaducts are used for the southern section of the high-speed railway (HSR) project that passes through the southwestern plain of Taiwan to minimize the use of lands and the possible obstacles to the eastwest transportation. However, the southwestern plain has poor soil conditions and is also a seismic active zone. Hence, deep foundations are considered for the viaduct structures. In order to understand more about the behavior of the pile foundations installed in this section, prototype pile load tests were conducted during the design stage. The selected site for this pilot pile test is located in Taipao, Chiayi County. Typical soil simplified profiles and parameters in the test site are shown in Table 1. Layout of the tested piles and pile groups are shown in Fig. 4. Ground water table is about $1 \mathrm{~m}$ below the original ground surface (GL.0 m). Water contents are in the range of $20 \%$ to $30 \%$ [2]. Two groups of piles were considered. One of the pile groups consists six drilled shafts (designated as B3-B8), each of which has the diameter of $1.5 \mathrm{~m}$ and length about $35 \mathrm{~m}$. The other group consists of 12 driven precasted concrete piles (designated as $\mathrm{P} 1-\mathrm{P} 12$ ) that are $0.8 \mathrm{~m}$ in diameter and $34 \mathrm{~m}$ long. The cap size of the drilled shaft group is $12 \mathrm{~m}$ long, $8.5 \mathrm{~m}$ wide, and $2 \mathrm{~m}$ thick. The precasted pile group has the cap of $9 \mathrm{~m}$ long, $8 \mathrm{~m}$ wide and $2 \mathrm{~m}$ thick. The two groups are $12 \mathrm{~m}$ apart. For the lateral group pile load test, a loading frame was installed between the two pile caps to exert lateral loadings. In addition, seven other drilled shafts (designated as B1, B2, and B9-B13) and one precasted pile (P13) were also installed next to the pile groups for other purpose. In general, each of the piles in the group is equipped with an inclinometer and some pairs of rebar gages to measure the lateral deflection and the variation of axial stresses along the pile shaft [2].

Since the purpose of this paper is to investigate the effect of material and geometric nonlinearity on lateral behavior of drilled shaft, only B2 shaft is simulated, evaluated and studied in details in this paper. The length and the diameter of this B2 shaft, installed using the casing method, are $34.9 \mathrm{~m}$ and $1.58 \mathrm{~m}$, respectively. The elevation of pile head is the same with original ground surface $($ GL.0 $\mathrm{m}$ ) that is above $1 \mathrm{~m}$ of the practical ground surface (GL.-1 m) during the lateral loading test. Seven loading cycles were incrementally applied about $0.5 \mathrm{~m}$ below the pile head and in the order of 196, 392, 549, 854, 1,158, 1,462, and 2,541 kN. Under the maximum applied load, the respective head displacement is $142.27 \mathrm{~mm}$, which is about 9 percent of the shaft diameter. Most of the shaft deflection exists around the pile head to the depth of $11 \mathrm{~m}$ below ground surface. The maximum tensile and compressive stresses are occurred at the shaft locations of $5 \mathrm{~m}$ and $8 \mathrm{~m}$ below pile head, based on the rebar gage measurements [2].

Material parameters used for the B2 shaft numerical analyses are listed in Table 2. The locations and the properties of the reinforcements of B2 shaft, given in Fig. 5 [2], are modeled and simulated in the nonlinear 
Table 2. Material parameters on HSR laterally loaded drilled-shaft B2

\begin{tabular}{cccccc|cccc}
\hline \multirow{2}{*}{$\begin{array}{c}\text { Bored } \\
\text { Pile }\end{array}$} & $\begin{array}{c}\text { Area } \\
\left(\mathrm{m}^{2}\right)\end{array}$ & $f_{c}^{\prime}(\mathrm{MPa})$ & $f_{r}(\mathrm{MPa})$ & $E_{c}(\mathrm{GPa})$ & $v$ & $f_{y}(\mathrm{MPa})$ & $E_{s}(\mathrm{GPa})$ & $v$ \\
\hline B2 & 1.961 & 27.468 & 3.283 & 24.623 & 0.18 & 412.02 & 200.124 & 0.29 \\
\hline
\end{tabular}

* The equivalent elastic moduli of three shaft sections are $32.84 \mathrm{GPa}, 30.1 \mathrm{GPa}$ and $27.36 \mathrm{GPa}$ respectively in the linear analysis (constant EI) under varied laterally loading levels.

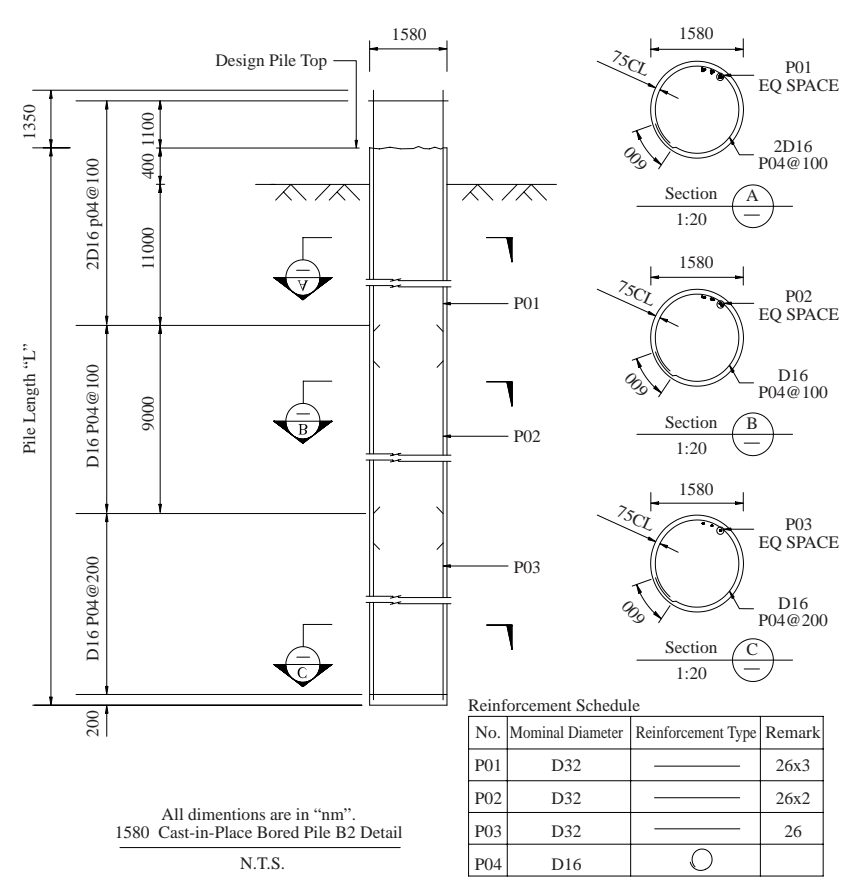

Fig. 5. Details of cast-in-place drilled shaft for B2 [2].

analysis (nonlinear EI) as detailed in Fig. 3. Moreover, evaluation for the lateral performance of drilled shaft is found to be affected by the factors of nonlinearity in shaft materials, the various equivalent elastic moduli for each shaft sections, which are obtained by transforming the flexural rigidity of various shaft sections from different materials and their contents, are used in the linear analysis that treats drilled shaft as elastic material and held constant (constant EI) under varied laterally loading levels. These moduli are also listed below the Table 2 .

Following the conclusion of the study by Chu [5], the boundary between the near and the far field is assumed to be the distance of fifteen shaft diameters (i.e. $s=30 \mathrm{r}$, where $r$ is shaft radius) away from the centered axis of pile shaft. The calculated deflection and the soil plastic strain zones around the shaft under maximum applied loading are shown in Fig. 6. It also indicates the ground displacement at distance of $15 \mathrm{~m}$ (about 10 times of shaft diameter) away from the shaft

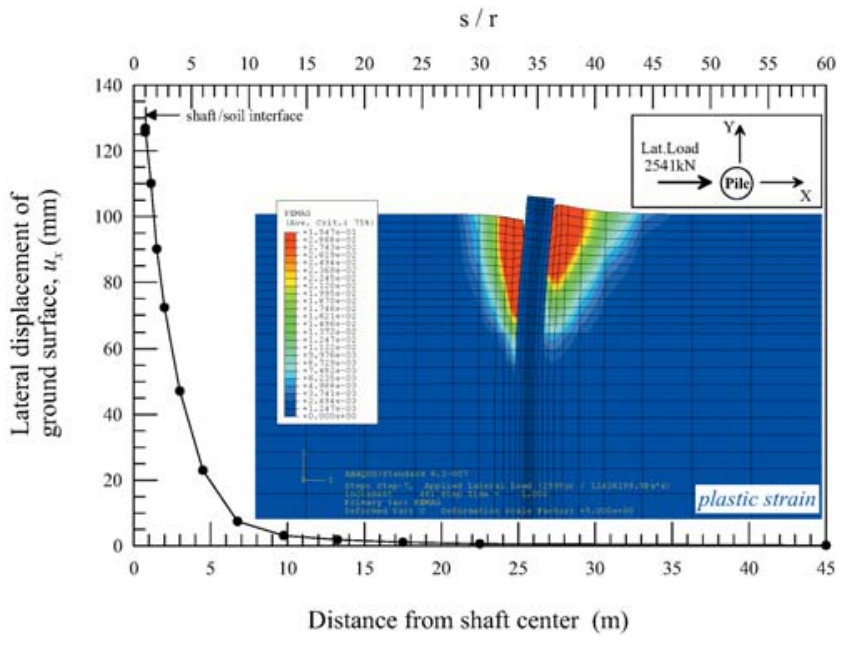

Fig. 6. Displacement of ground surface and plastic strain profile of soil under the maximum laterally loading level.

center, which is less than $1.5 \mathrm{~mm}$ and its corresponding strain is only about $0.018 \%$. In addition, the contour diagram of the soil plastic strain zone shows the soil yields within the distance of six times of shaft diameter. Since ground displacement at location of fifteen times of the shaft diameter from the shaft center approaches zero, hence the assumed boundary between near and far field is appropriate.

\section{DISCUSSION ON THE NUMERICAL RESULTS}

Based on the numerical simulation and analysis, the calculated and the measured pile head loads vs. displacement relationship is shown in Fig. 7. Apparently, possible concrete cracking of the shaft significantly affects the calculated results. If concrete cracking effect is neglected in the numerical analysis, the results tend to overestimate the capacity of the shaft. Ground deflections along and perpendicular to the loading direction under varied loading levels are shown in Fig. 8, in which $u_{x}$ and $u_{\text {pile }}$ represent the soil and the pile head displacement along the loading direction, respectively. As shown in the figure, the ratio of $u_{x}$ to $u_{\text {pile }}$ decreases along the distance away from the centered axis of pile shaft. Even under the maximum loading, the affected 
ground distance in the loading direction is mainly within about eleven times of shaft diameter from the shaft center. Regarding the ground surface displacement in the direction perpendicular to the loading direction, some discontinuities appear at the shaft/soil interfaces as a result of interaction. The discontinuities indicate that separation at shaft and soil interfaces may have occurred because of relative movement, which also results in faster displacement reduction rate at ground surface. In addition, it is also found that the displacement decreasing rate along the load direction appears to be more severe with increasing load level. Furthermore,

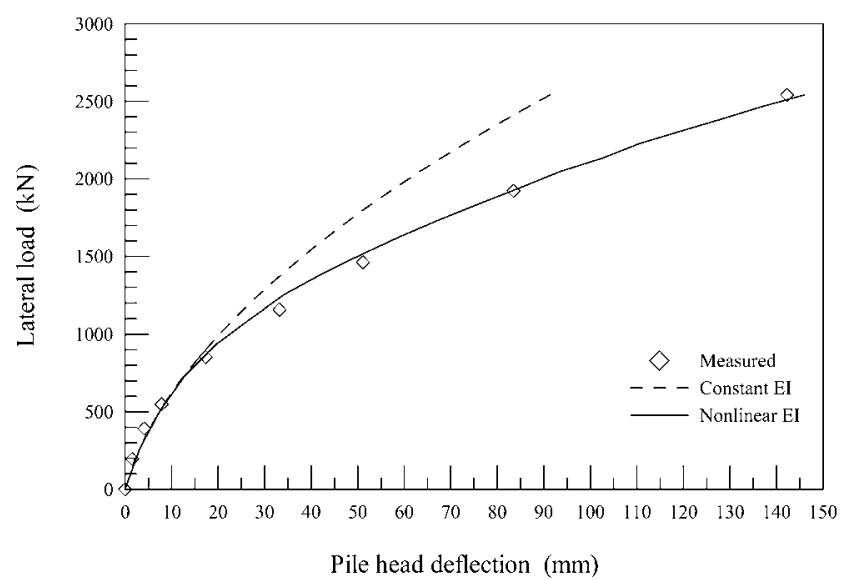

Fig. 7. Displacement of pile head under lateral load. with increasing loading level, the changing of displacement perpendicular to the loading direction on ground surface tends to localize the opposite direction and the soil displaces on ground surface opposite to the loading direction due to the shaft pushing.

The calculated deflection, bending moment, shear force and soil resistance along the shaft are given in Fig. 9. The measured and the calculated deflections along the shaft under different loading levels are in

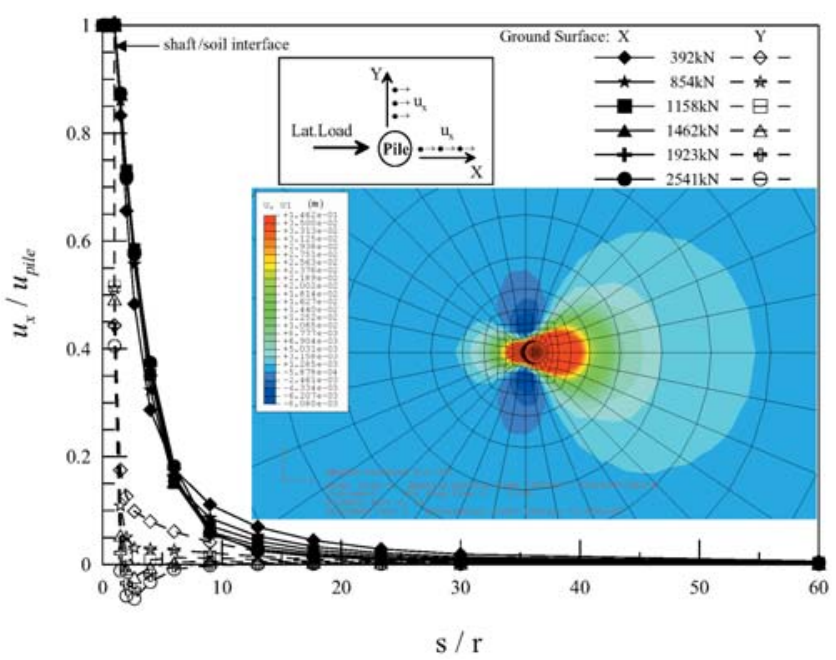

Fig. 8. Variant displacement of ground surface under different loading levels.

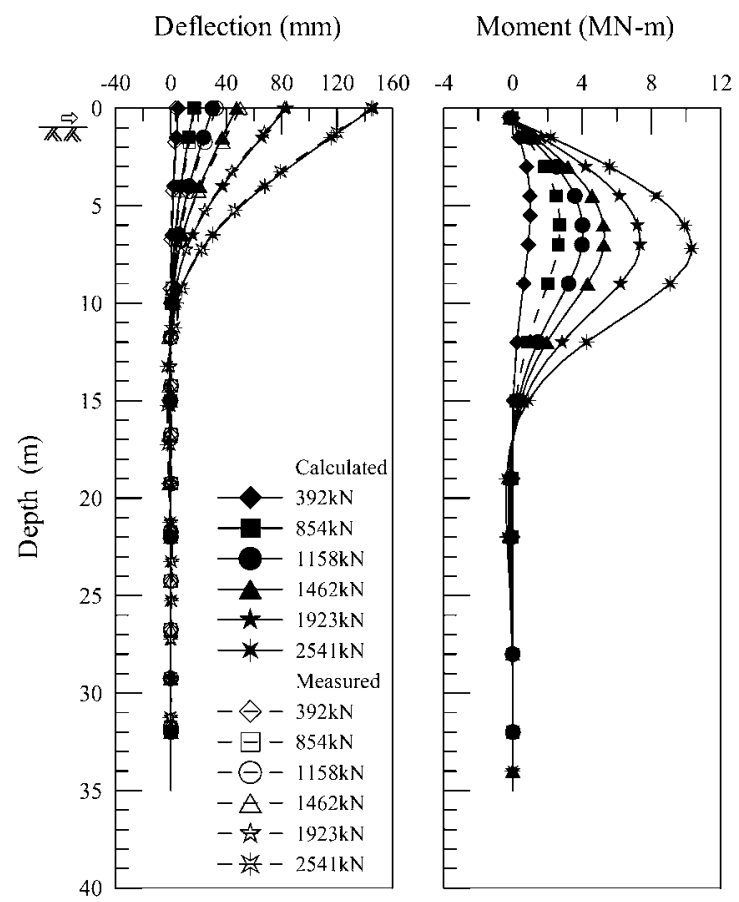

Shear Force $\left(\times 10^{2} \mathrm{kN}\right) \quad$ Soil Resistance $\left(\times 10^{2} \mathrm{kN} / \mathrm{m}\right)$
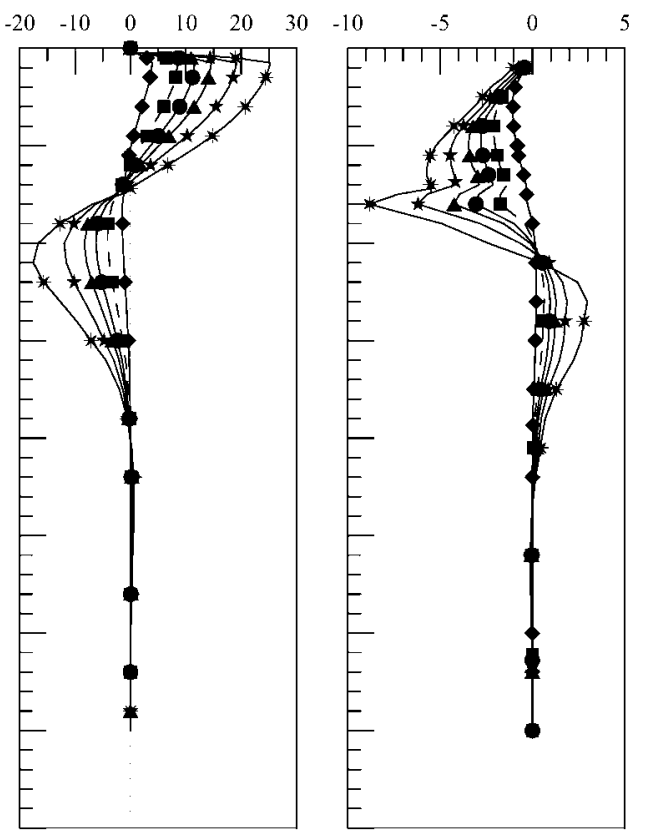

Fig. 9. Analyzed results on laterally loaded drilled-shaft. 


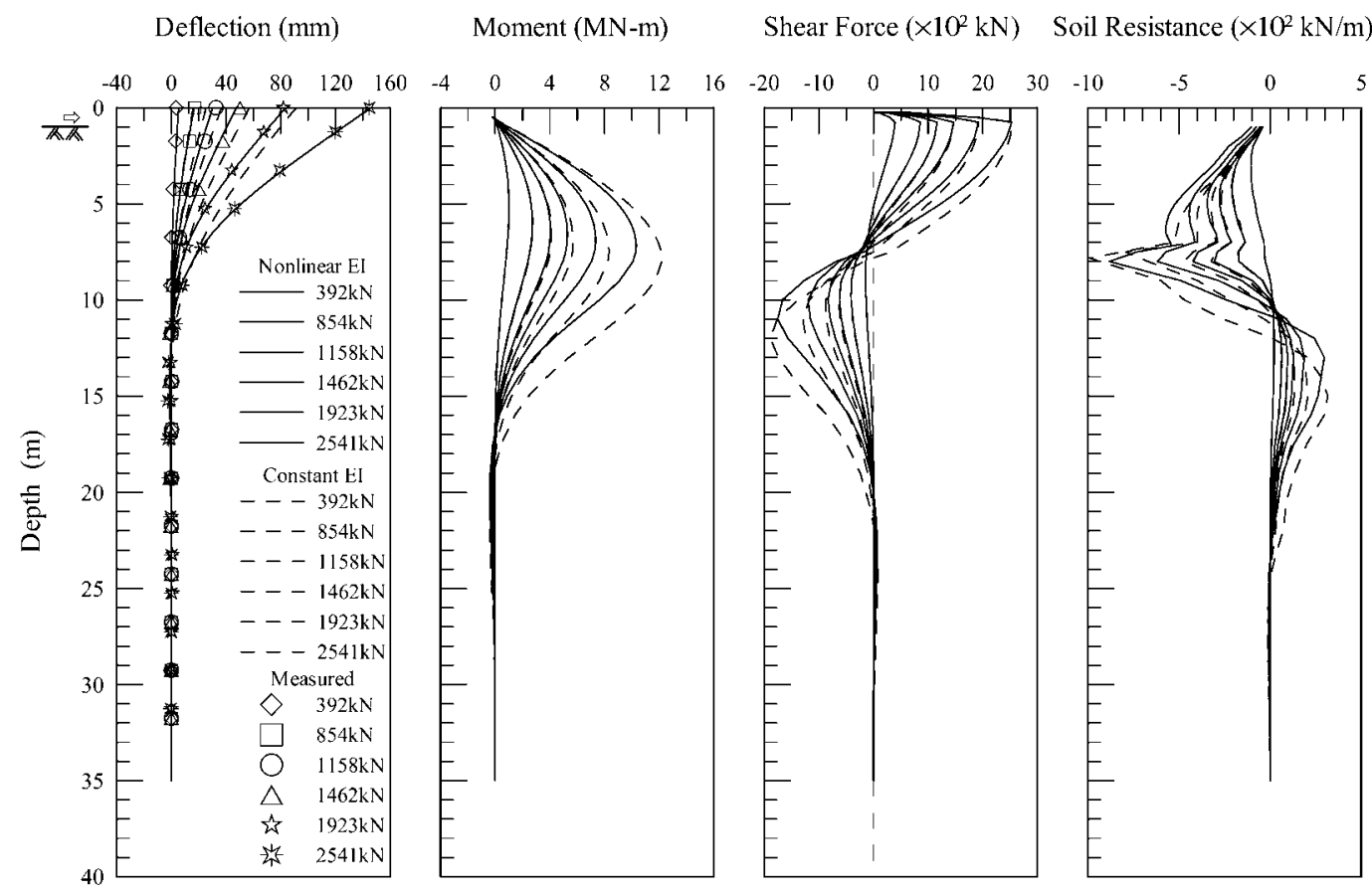

Fig. 10. Comparisons of analyzed results on laterally loaded drilled-shaft.

good agreement. For comparison purposes, how the effect of shaft cracking on shaft/soil interaction performance is also presented in Fig. 10. Based on this figure, neglecting the nonlinear shaft behavior tends to underestimate the deflection around pile head and overestimate the bending moments when loading level is higher than $854 \mathrm{kN}$. In addition, the linear shaft assumption (constant EI) also affects the shaft shear force distribution and the soil resistance estimation as given in Fig. 10. Therefore, the importance of considering nonlinear structural material behavior is quite obvious, according to the numerical results. Good agreement is also found for the calculated and the measured slope along the shaft length as given in Fig. 11. Variations of the moment curvature relationships are given in Fig. 12. Based on these calculated results, we can see that shaft rigidity EI is significantly affected by the concrete cracking of shaft. The estimated shaft cracking moment is about $1,700 \mathrm{kN}-\mathrm{m}$, which matches the shaft properties of materials and geometry given in Fig. 5. The cracking and the yielding moments of the shaft given in Fig. 5 may be computed as 1,695.6 kN-m and approximate above $10,830 \mathrm{kN}-\mathrm{m}$, respectively. When lateral load increases to $854 \mathrm{kN}$, the bending moments of the shaft at depth $3 \mathrm{~m}$ to $9 \mathrm{~m}$ (Fig. 9) apparently exceed their cracking moment, resulting in some local concrete cracking in the shaft. The concrete cracking effect is more severe and spreading up- and downward when the applied lateral loading is

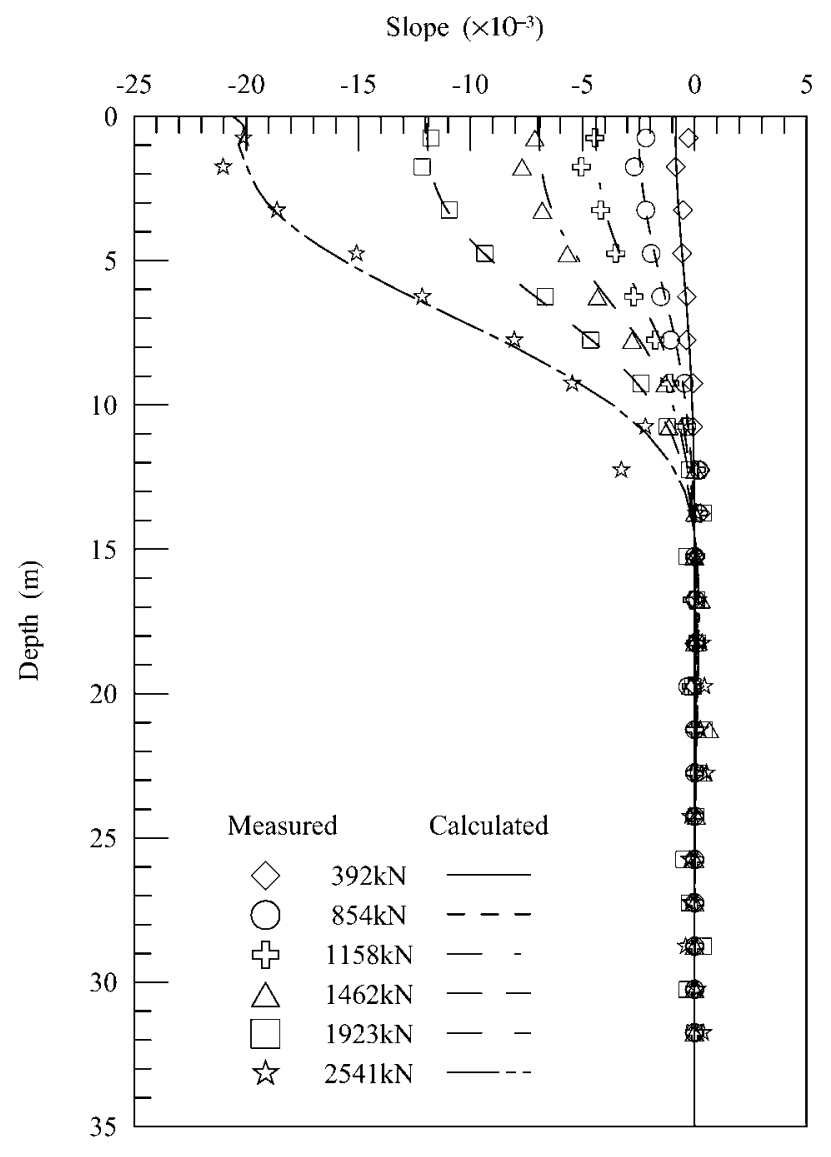

Fig. 11. Variation of slope along the shaft. 


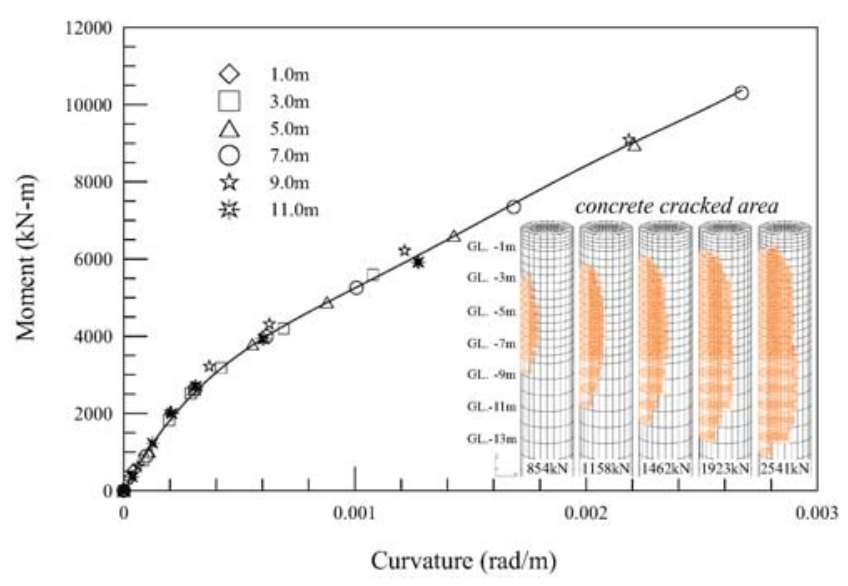

Fig. 12. Variations of moment and curvature with concrete cracked area along the shaft.

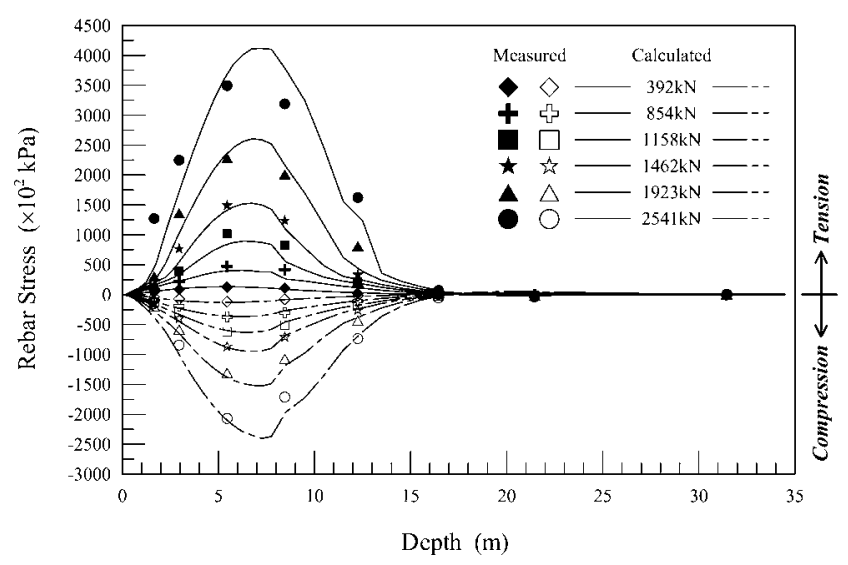

Fig. 13. Stress distribution of rebar along the shaft.

increased, as shown in Fig. 12. The measured and the calculated rebar stresses under different loading levels are given in Fig. 13. The maximum values, as well as the measured results, are between $5 \mathrm{~m}$ and $7.5 \mathrm{~m}$ below pile head, apparently. Figs. 14 and 15 give the calculated results on soil movement around the shaft under different loading levels. As shown in Fig. 14 , the ground soil in front of the shaft in the loading direction tends to move upward. The value of the upward movement increases with increased loading level. The maximum uplift at maximum loading of $2,541 \mathrm{kN}$, is $113.48 \mathrm{~mm}$, which occurs at the location about three quarters of shaft diameter from the centered axis of pile shaft (i.e. $s \approx 1.5 \mathrm{r}$ ). The uplift diminishes at location about five times of shaft diameter from shaft center. Shaft/soil separation is found behind the rear side of the shaft. In addition, as indicated in Fig. 15, the depth of separation behind the shaft increases with increased loading level. At maximum loading level of

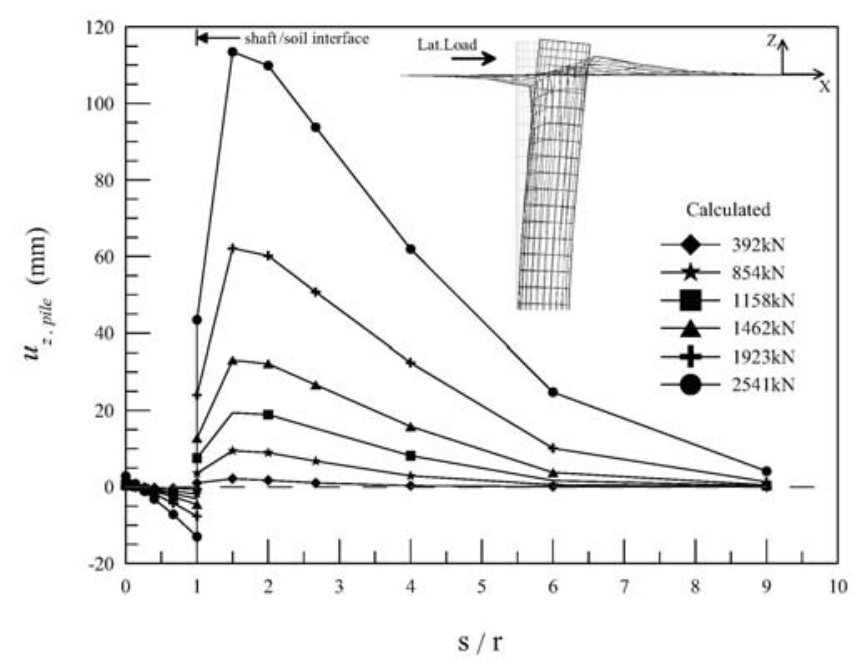

Fig. 14. Upward movement of ground soil in front of the laterally loaded shaft.
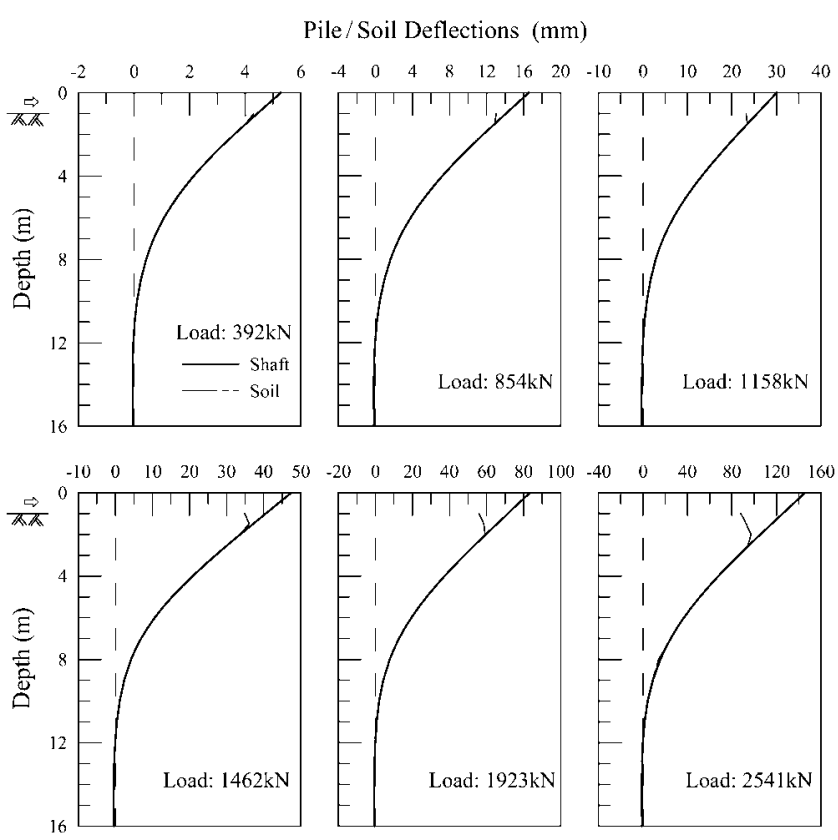

Fig. 15. Separated state between shaft and rear soil under different loading levels.

$2,541 \mathrm{kN}$, the depth of separation is about $2 \mathrm{~m}$ downward from the ground surface.

\section{CONCLUSIONS}

By adopting the available finite element code, ABAQUS, and also considering nonlinearity of structure and material properties of both soil and shaft for a laterally loaded drilled-shaft analysis, some conclu- 
sions can be drawn in the following:

1. The models used to represent the structural geometry and material properties are capable of simulating the lateral behavior of drilled shaft under nonlinear conditions.

2. The importance of including the effect of concrete cracking on drilled shaft behavior due to lateral loading has also been shown. For the numerical case simulated and examined, the shaft cracked at loading level of $630 \mathrm{kN}$. The respective deflection is $10.1 \mathrm{~mm}$ only, which shows that the elastic performance of shaft can be kept merely within very small displacement range. Neglecting the nonlinear behavior of structure and material will overestimate the lateral shaft capacity.

3. The ground soil uplift in front of the shaft along the loading direction increases with increased loading level. However, the maximum amount of ground soil uplift is not located at the closed soil/shaft interface, it occurs at the adjacent place in front of the shaft, probably caused by the friction between the shaft and the soil.

4. Pile group behavior is much more complicated than that of a single pile. The factors on performance of laterally loaded single pile presented in this paper also affect the behavior of a pile group. How these factors affect the performance or response of pile group subjected to lateral loading are important and need further investigation.

\section{ACKNOWLEDGMENT}

The authors would like to thank the tested data provided from the Bureau of Taiwan High Speed Rail and the supports of the National Center for High-performance Computing (NCHC) for their computing programs and servers that are used in this study.

\section{REFERENCES}

1. ACI Committee 318, Building Code Requirements for Structural Concrete (ACI 318-95) and Commentary
(ACI 318R-95), American Concrete Institute (1995).

2. Bureau of Taiwan High Speed Rail, "Optimal Design for Bridge Foundation of HSR Project," TCRI Report, No. 2-0-86-05-02-165, Taipei, Taiwan, R.O.C. (1997).

3. Chen, L. and Poulos, H.G., "Analysis of Pile-soil Interaction Under Lateral Loading Using Infinite and Finite Elements," Computers Geotech., Vol. 15, No. 4, pp. 189 220 (1993).

4. Chiou, J.S., "The Research of Behavior on Laterally Loaded Piles," Ph.D. Dissertation, Department of Civil Engineering, National Taiwan University, Taipei (2001).

5. Chu, H.J., "Analysis of Nonlinear Behavior on Laterally Loaded Piles," Ph.D. Dissertation, Department of Civil Engineering, National Taiwan University, Taipei, p. 284 (2000).

6. Hibbit, H.D., Karlsson, B.I., and Sorensen, P., ABAQUS Theory and User's Manual, Version 6.2, Hibbit, Karlsson, and Somsen, Inc., Pawtcket, RI, U.S.A. (2002).

7. Lin, S.S., "Use of Filamented Beam Elements for Bored Pile analysis," J. Struct. Engin., ASCE, Vol. 123, No. 9, pp. 1236-1244 (1997).

8. Lin, S.T., "Analysis of Laterally Loaded Cast-in-place Piles Considering Concrete Cracking," Master Thesis, Department of Construction Engineering, National Taiwan University of Science and Technology, Taipei, p. 147 (1998).

9. MacGregor, J.G., Reinforced Concrete: Mechanics and Design, Prentice Hall Englewood Cliffs, NJ, U.S.A. (1988).

10. MSC.Software, MSC/PARTAN User's Guide, Version 2001 (r3), MacNeal- Schwendler Corporation, Santa Ana, CA, U.S.A. (2001).

11. Ng, C.W.W., Zhang, L., and Nip, D.C.N., "Response of Laterally Loaded Large-diameter Bored Pile Groups," J. Geotech. Geoenviron. Engin., ASCE, Vol. 127, No. 8, pp. 658-669 (2001).

12. Reese, L.C. and Wang, S.T., "Analysis of Piles Under Lateral Loading with Nonlinear Flexural Rigidity," Proceedings International Conference on Design and Construction of Deep Foundation, FHWA, Vol. 2, pp. 842-856 (1994). 